\title{
TOPICAL FUNCTIONS: HERMITE-HADAMARD TYPE INEQUALITIES AND KANTOROVICH DUALITY
}

\author{
M. H. DARYAEI AND A. R. Doagooei
}

Abstract. For a certain class of elementary functions consisting of min-type functions, we apply techniques from abstract convex analysis to study Hermite-Hadamard type inequalities for increasing and plus-homogeneous (topical) functions. Some examples of such inequalities for functions with the special domains are given as well. In the next part, we study Kantorovich duality for the optimal mass transportation problems whenever the cost function is a min-type function. In this case, some pricing criteria are established as well.

Mathematics subject classification (2010): 26D15, 26A51, 90C08, 90C46.

Keywords and phrases: Abstract convexity, Hermite-Hadamard type inequalities, topical function, optimal transportation, Kantorovich duality.

\section{REFERENCES}

[1] G. R. Adilov AND S. Kemali, Hermite-Hadamard type inequalities for increasing positively homogeneous functions, Journal of Inequalities and Applications, (2007) Article ID: 21430.

[2] S. BARTZ And S. Reich, Abstract convex optimal antiderivatives, Annales de L'Institut Henri Poincaré (C) Non Linear Analysis 29 (2012), 435-454.

[3] S. Bartz and S. Reich, Optimal Pricing for Optimal Transport, Set-Valued and Variational Analysis 22 (2014), 467-481.

[4] G. Buttazzo And G. Carlier, Optimal spatial pricing strategies with transportation costs, Contemporary Math. 514 (2010), 105-121.

[5] A. R. Dohgooei AND H. Mohebi, Optimization of the difference of topical functions, Journal of Global Optimization 57 (2013), 1349-1358.

[6] S. S. Dragomir, J. DutTa AND A. M. Rubinov, Hermite-Hadamard type inequalities for increasing convex-along-rays functions, Analysis 24 (2004), 171-181.

[7] S. S. Dragomir, J. E. PeČArić and L. E. Persson, Some inequalities of Hadamard type, Journal of Mathematics 21 (1995), 335-341.

[8] A. Fiagalli, Y.-H. Kim AND R. J. MCCANn, When is multidimensional screening a convex program?, J. Econom. Theory 146 (2011), 454-478.

[9] J. Gunawardena, An Introduction to Idempotency, Cambridge University Press, Cambridge, 1998.

[10] J. HADAMARD, Étude sur les propriétés des fonctions entières et en particulier d'une fonction considérée par Riemann, Journal de Mathématiques Pures et Appliquées 58 (1893), 171-215.

[11] V. M. Kermani AND A. R. DoAgooei, Vector topical functions and Farkas type theorems with applications, Optimization Letters 9 (2015), 359-374.

[12] H. Mohebi AND M. SAMET, Abstract convexity of topical functions, Journal of Global Optimization 58 (2014), 365-375.

[13] C. E. M. Pearce And A. M. Rubinov, P-functions, quasi-convex functions, and Hadamard-type inequalities, Journal of Mathematical Analysis and Applications 240 (1999), 92-104.

[14] A. M. Rubinov, Abstract Convex Analysis and Global Optimization, Kluwer Academic Publishers, Boston, Dordrecht, London, 2000.

[15] A. M. Rubinov And I. Singer, Topical and sub-topical functions, downward sets and abstract convexity, Journal of Optimization 50 (2001), 307-351. 
[16] S. T. Rachev and L. RÜschendorf, Mass Transportation Problems, vol. I: Theory, Probability and its Applications, Springer Science \& Business Media, 1998.

[17] S. T. RACHeV And L. RÜSChendorf, Mass Transportation Problems, vol. II: Applications, Probability and its Applications, Springer Science \& Business Media, 1998.

[18] I. Singer, Abstract Convex Analysis, Wiley-Interscience, New York, 1997.

[19] E. V. SHARIKOV, Hermite-Hadamard type inequalities for increasing radiant functions, Journal of Inequalities in Pure and Applied Mathematics 4 (2003), 1-13.

[20] C. Villani, Optimal Transport: Old and New, Springer, Berlin, 2009. 